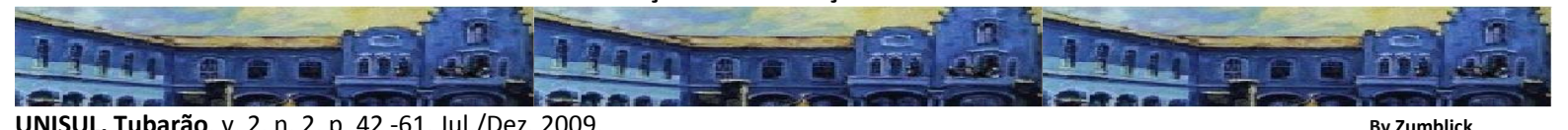

\title{
PROJECTOS COLONIAIS E SEUS EFEITOS: O CASO DO TRABALHO DE JOSÉ REDINHA DESENVOLVIDO NO MUSEU DO DUNDO ${ }^{1}$
}

Patrícia Ferraz de Matos ${ }^{2}$

\section{RESUMO}

A partir da exposição Lunda - Tchokwe, integrada na Trienal de Luanda, procurarei dar a conhecer um pouco melhor a figura de José Redinha (1905-1983), um importante etnógrafo que produziu vários trabalhos e relatórios sobre diversas zonas culturais de Angola, e o trabalho que este desenvolveu enquanto funcionário, primeiro como empregado e depois como conservador, no Museu do Dundo, que esteve sob o controle da Companhia de Diamantes de Angola até 1975.

\section{Palavras-chave}

Museu do Dundo; Luanda; Cultura; Arte Tchokwé.

\section{SUMÁRIO}

No final de 2006 visitei a inauguração da exposição Lunda - Tchokwe, integrada na Trienal de Luanda. Estiveram em exposição 99 quadros reproduzidos a partir da obra, há muito esgotada, intitulada "Subsídios para a história, arqueologia e etnografia dos povos da Lunda - paredes pintadas da Lunda" (1953), da autoria de José Redinha. Alguns artistas angolanos contemporâneos referiram na altura que aqueles trabalhos foram influentes e determinantes nas suas obras. Durante a minha visita constatei ainda que aqueles quadros despertavam emoções e até manifestações positivas em alguns visitantes face aos desenhos, que podiam ser encaradas como motivadoras da auto-estima dos angolanos e inspiradoras de novos artistas plásticos.

Neste texto irei procurar dar a conhecer um pouco melhor a figura de José Redinha (1905-1983), um importante etnógrafo que produziu vários trabalhos e relatórios sobre

\footnotetext{
${ }^{1}$ Uma versão mais ampliada deste texto foi publicada no livro: Muleka Mwewa. (org.). África e suas diásporas: olhares interdisciplinares. São Leopoldo: Nova Harmonia, 2008. Agradecemos a Editora Nova Harmonia em nome do seu editor chefe Professor Doutor Antônio Sidekum por ter autorizado a publicação de parte deste texto nesta revista. Este trabalho foi financiado pela Fundação para a Ciência e a Tecnologia (FCT).

${ }^{2}$ Doutoranda do Instituto de Ciências Sociais da Universidade de Lisboa e Bolseira da Fundação para a Ciência e a Tecnologia.
} 
diversas zonas culturais de Angola, e o trabalho que este desenvolveu enquanto funcionário, primeiro como empregado e depois como conservador, no Museu do Dundo, que esteve sob - controle da Companhia de Diamantes de Angola até 1975. Nesse sentido irei contextualizar esta personagem e a sua acção no contexto mais vasto que é o do período colonial português da primeira metade do século XX e tentarei perceber como algumas iniciativas, já criticadas ou questionadas, levadas a cabo nos anos 40 e 50 por figuras do colonialismo português, como José Redinha, que durante muito tempo foram esquecidos ou ignorados, são agora lembradas ou começam a produzir alguns efeitos, ainda que inesperados e surpreendentes no que diz respeito a aspectos que envolvem questões relativas à identidade, influência cultural, hibridez e pós-colonialismo.

\section{VELHOS PROJECTOS, NOVOS TEMAS DE REFLEXÃO}

A realização do trabalho que está por detrás deste capítulo foi motivada pela visita a uma exposição quando me desloquei a Luanda, entre Novembro e Dezembro de 2006, e fui convidada a estar presente na inauguração da Exposição Lunda - Tchokwé ${ }^{3}$, integrada na Trienal de Luanda (figura n. 1). Essa exposição, dividida por várias salas da cidade, era composta por 99 serigrafias extraídas das imagens da obra "Subsídios para a história, arqueologia e etnografia dos povos da Lunda ${ }^{4}$ - paredes pintadas da Lunda", editada pelo Museu do Dundo em 1953, da autoria de José Redinha, e há muito tempo esgotada 5 , embora algumas pessoas tenham movido esforços junto das entidades competentes para que a obra fosse reeditada. As salas pelas quais a exposição se distribuía tinham sido preparadas especialmente para o efeito (figura n.ㅇ 2). Nesse sentido, tanto as paredes como o chão das mesmas tinham sido arranjados de igual modo, sendo as paredes pintadas de branco e o chão de cinzento, todas as molduras dos quadros eram feitas do mesmo material e a decoração luminosa era idêntica.

Na sala onde decorreu a inauguração encontravam-se jornalistas da televisão e da imprensa local, procurando entrevistar alguns dos visitantes. Constatei na altura que alguns

\footnotetext{
${ }^{3}$ Tchokwé, quioco, cokwe ou kioko são designações diferentes, mas que se atribuem ao mesmo grupo.

${ }^{4}$ No âmbito das Publicações culturais da Companhia de Diamantes de Angola existem vários trabalhos com o título "Subsídios para a história, arqueologia e etnografia dos povos da Lunda" que têm distintos subtítulos especificando o seu conteúdo.

${ }^{5}$ Recentemente, tomei conhecimento de que a obra vai ser finalmente reeditada em Angola.
} 
artistas plásticos angolanos contemporâneos referiam nas entrevistas, e conversando com outras pessoas, que aqueles trabalhos foram influentes e determinantes nas suas obras. Além disso, e ao longo da minha visita repartida pelas várias salas, observei que aqueles quadros despertavam emoções e até manifestações positivas em alguns visitantes quando visionavam os desenhos, as formas e as suas cores, um facto que podia ser encarado como motivador e elevador da auto-estima dos angolanos e inspirador dos novos artistas plásticos. Outros visitantes falavam em ir procurar e conhecer o seu passado e encontrar a sua identidade.

Posteriormente a esta minha visita, tomei a iniciativa de tentar perceber este fenómeno cultural, a partir de uma manifestação artística - as paredes pintadas das casas dos lundas-tchokwé - recolhidas nos anos 40 e inícios dos anos 50 do século XX por José Redinha. Depois do que vi e ouvi em Luanda considero que este é um tema relevante sobre o qual reflectir presentemente e o VI Congresso de Estudos Africanos no Mundo Ibérico pareceu-me um local privilegiado para apresentar as questões que me foram surgindo e debatê-las publicamente. Esta exposição é, como diria Lévi-Strauss, "boa para pensar" e para reflectirmos sobre o que se está a passar na África pós-colonial e, especificamente, em Angola.

\section{A DIVULGAÇÃO DA EXPOSIÇÃO}

Segundo o guia da exposição (figura n.ำ 1), esta tratava-se de uma "edição de serigrafia electrónica sobre tela, das pinturas Lunda-Tchokwé a partir das ilustrações de José Redinha" em que as obras com "imagens representativas dos primeiros registos da pintura Lunda-Tchokwé" teriam a "dimensão equivalente a três metros quadrados de superfície, respeitando as suas dimensões originais". Por outro lado, acrescentava que a Trienal de Luanda propunha "analisar o trabalho de investigação sobre a estética pictórica e filosófica dos povos da região Lunda, extraídas do livro" referido. Porém, ao longo da exposição, para além da amostra dos próprios quadros, não é divulgada qualquer análise, contextualização ou apreciação dos mesmos. O guia acrescenta que "é urgente uma releitura do mesmo fenómeno numa perspectiva contemporânea e sem preconceitos", refere que este espólio permite "a cada um de nós descodificar esta proposta estética e a sua contemporaneidade 
da expressão artística no início do século XX em Angola" e procura alimentar a "expectativa de que a obra intervenha e circule como referência histórica do imaginário Lunda".

De acordo com o guia, esta era uma proposta de "reajuste cultural no registo das artes plásticas angolanas". Além disso, e "pelo inegável valor do espólio", a Trienal de Luanda iria "consagrar esta edição ao Estado Angolano, propondo integrá-lo no Tesouro Nacional como Coleç̧ão Oficial de Estado" e constitui-lo como "um primeiro espólio representativo das Artes Primeiras de Angola". Por último, o guia enfatizava a importância da cultura e das artes plásticas ao permitir "sinergias positivas à vida da nação". É dado destaque ao "momento cultural actual da nação" e à necessidade de promover "o conhecimento, a divulgação, bem como a valorização da expressão artística angolana, propondo um mecanismo de política cultural que eleve a auto-estima do indivíduo na sociedade".

Estava assim explicitado o teor da exposição e o seu principal objectivo - elevar a auto-estima dos angolanos e divulgar a cultura angolana a partir destas manifestações artísticas. No entanto, o que ali não fica claro é como aqueles trabalhos produzidos e associados ao grupo tchokwé, de certa forma circunscrito na imensidão geográfica, étnica e cultural de Angola, podiam ser representativos da cultura angolana vista como um todo e ter um papel fundamental no que diz respeito à afirmação da nação angolana.

Por seu turno, o jornal Angoflash ${ }^{6}$, editado pela embaixada da República de Angola na Rússia (Serviço de Imprensa, Moscovo/ Rússia), de 28 de Novembro de 2006, noticiava a exposição na secção de "Cultura" referindo que aquela se tratava de uma "primeira experiência" e que o evento se enquadrava "num processo de resgate e de absorção cultural", destinado "a uma análise do trabalho de investigação sobre a estética pitoresca e filosófica dos povos da região Lunda". A exposição foi também anunciada na Internet pela organização da trienal ${ }^{7}$ incluindo os propósitos já referidos.

Para compreendermos melhor estas obras é importante começarmos por conhecer o contexto no qual elas foram recolhidas, nos anos 40 e 50 do século XX, quando Angola era ainda administrada por Portugal.

\footnotetext{
${ }^{6}$ Vide http://angolarussia.ru/press/angoflash/angoflash_2006-11-28.doc.

${ }^{7}$ Vide http://www.trienal-de-luanda.net/index.php?cat=2.
} 


\section{O COLONIALISMO PORTUGUÊS, A DIAMANG E O MUSEU DO DUNDO}

Como se sabe, o colonialismo português é um colonialismo tardio. De facto, a colonização moderna de África e a sua ocupação efectiva é, em termos históricos, recente e no que se refere a Portugal inscreve-se no âmbito do que é habitualmente designado por Terceiro Império Português (1890-1974) (Telo 1994: 205-207). Ainda assim a referência ao colonialismo português deverá ser contextualizada enquanto "situação histórica" 8 e da qual fazem parte factos e pessoas concretas que tiveram um papel determinante (podendo esse ser considerado positivo ou negativo). Como referiu o historiador de África Frederick Cooper (2005), a história do colonialismo não deve ser feita de modo a-histórico, genérico ou abstracto, e necessita de ter em conta as necessárias diferenças entre os actores do passado e os "intérpretes" do presente.

Durante o período do Terceiro Império Português é interessante verificarmos a excepcionalidade do trabalho desenvolvido no Museu do Dundo, administrado pela Diamang, num contexto em que são desenvolvidos parcos estudos ou investigações, por falta de interesse e/ ou escassez de recursos materiais e humanos, sobre o contexto colonial. A Diamang ${ }^{9}$ - Companhia de Diamantes de Angola - foi fundada em 1917 e dissolvida na sequência da afirmação da República Popular de Angola como estado independente, que ocorreu a 11 de Novembro de $1975^{10}$. Foi constituída com capitais portugueses (da firma Henry Burnay \& Ca., depois Banco Burnay e do Banco Nacional Ultramarino), belgas (da Société Générale de Belgique e da Mutualité Coloniale), franceses (da Banque de I'Union Parisienne), e dos Estados Unidos da América (o grupo Ryan-Guggenheim). A sede era em Lisboa, mas a Companhia tinha escritórios em Bruxelas, Londres e Nova lorque. Segundo Nuno Porto,

[Do seu] conselho de Administração, faziam parte, inicialmente, o BNU, Ernesto Vilhena, como Administrador-Delegado, o Banco Burnay, representantes da Société Génerale de Belgique, um representante da empresa mineira belga, Forminière, o Presidente do Sindicato de Diamantes de Londres; um representante da Anglo American Corp., um representante da Banque de L'Union Parisienne e '(...) outras individualidades em

\footnotetext{
${ }^{8}$ Recorro aqui à expressão "situação colonial” definida primeiramente por Balandier (1955).

${ }^{9}$ A Diamang sucedeu "a uma empresa de prospecção, a PEMA - Pesquisas Mineiras de Angola - constituída em 1912, cujo propósito consistia na delimitação de jazidas diamantíferas no Nordeste de Angola, na bacia do Cassai.

${ }^{10} \mathrm{O}$ vizinho Congo tornou-se um estado independente em 1960.
} 
destaque na alta finança portuguesa e estrangeira' (cf. Leite de Castro, 1929: 3-4, apud Porto, 1999: 20).

A Diamang ocupava uma vasta área (cerca de $52.000 \mathrm{Km} 2$ ) que quase cobria as actuais províncias das Lundas Norte e Sul (figura n.ㅇ 3). A oeste e sul confinava com o restante território de Angola, a sudeste com a Zâmbia (Rodésia do Norte) e a norte e nordeste com a República Democrática do Congo (o então Congo Belga e depois Zaire). A doze quilómetros da República Democrática do Congo situava-se o Dundo, uma povoação fundada pela Diamang e "que constituía o seu centro administrativo na Lunda" (Porto, 1999: $1)$.

O Museu do Dundo ${ }^{11}$, que é hoje Museu Nacional, foi fundado em 1936 e esteve sob o controlo da Companhia até 1975. Já nos anos oitenta, e por ocasião da liquidação daquela, o espólio dos Serviços Culturais da Diamang foi adquirido, inventariado e publicado pelo Museu Antropológico da Universidade de Coimbra (MAUC, 1991). Este espólio "compreende, entre outros materiais, os Relatórios Mensais e Anuais do Museu e das secções com ele articuladas - o Laboratório de Investigações Biológicas e Secção de Arqueologia - e o Arquivo Fotográfico" (Porto, 1999: 2). Além disso, segundo Maria do Rosário Martins, conservadora do museu antropológico de Coimbra, e Maria Girão, em 1989 deu entrada no Museu e Laboratório Antropológico da Universidade de Coimbra um núcleo etnográfico proveniente do espólio cultural da Ex-Companhia de Diamantes de Angola "constituído por trezentos e quinze objectos de arte africana, distribuindo-se a sua área geográfica pela Lunda e povos vizinhos predominando, no entanto, objectos do grupo étnico “Cokwe'” (Martins \& Girão, 1995: 29). De acordo com Manuel Laranjeira Rodrigues de Areia, esta colecção etnográfica (esculturas, máscaras, esteiras e dois exemplares de cadeiras) é composta na sua maioria por "cópias de modelos antigos executados por escultores do Museu do Dundo que aplicaram técnicas, tipo estilístico e matérias-primas tradicionais" (Areia, 1995: 8).

A Diamang foi um empreendimento colonial que impressionou e causou impacto. Veja-se, por exemplo, a seguinte descrição de Luiz Carrisso, que participou em três missões botânicas a Angola (sendo a primeira em 1927 e a última em 1937), que revela claramente esse fascínio:

\footnotetext{
${ }^{11}$ O edifício do Museu do Dundo começou a ser construído em 1946 e terminou em 1950.
} 
No Dundo, sede da Companhia, na Lunda, em plena região diamantífera, pudemos todos apreciar a admirável organização de todos os serviços, que têm de prover às múltiplas necessidades de mais de cem funcionários brancos, e de alguns milhares de trabalhadores indígenas ${ }^{12}$ (...). Causa espanto o conforto das instalações, o apetrechamento tão completo e tão moderno das minas, naquele descampado no coração de África (1932: 15).

Em meados dos anos 30 "já habitavam no Dundo mais de 130 técnicos europeus e respectivas famílias" (Porto, 2000: 41). Por seu turno, "o crescimento de mão-de-obra nativa ultrapassara já os 5.000 homens nos anos 20 e levara à criação do cargo de Director Geral na Lunda" (idem, ibidem). Neste contexto, o Engenheiro Quirino da Fonseca, então Director Geral da Lunda foi sensibilizado pela "ideia segundo a qual as provas materiais da vida e arte nativas tendiam inexoravelmente a desaparecer e que, por isso, era urgente salvá-las" (Machado, 1995: 13).

Segundo o relatório anual do museu do ano de 1936, surge então a ideia de constituição de um “(...) Museu Gentílico no Dundo ${ }^{13}$ dedicado a armazenar e recolher todos os objectos característicos usados pela raças indígenas da área, especialmente Lundas e Quiocos" (RA 1936: 3, citado em Porto, 2000: 41). O Museu do Dundo passa a ser visto como "um projecto de salvação cultural" (Porto, 2000: 41) e com vista a viabilizar esse objectivo a Companhia contratou José Redinha, um assistente do Posto Administrativo da localidade próxima do Chitato, sede da Circunscrição, que estava a terminar a sua comissão de serviço. José Redinha viria a ser primeiro empregado e depois conservador do Museu do Dundo a partir de 1942.

O museu promoveu várias campanhas etnográficas e a partir de 1946 distribui os números das Publicações Culturais do Museu do Dundo "através das quais, mediante oferta" a academias e museus, o trabalho do museu será divulgado um pouco por todo o mundo"

\footnotetext{
12 Neste contexto, os indígenas eram, segundo o art.o 2 do Decreto 16: 473 de 6 de Fevereiro de 1929, do Ministério das Colónias, que regulamentou o Estatuto Político, Civil e Criminal dos Indígenas, "os indivíduos da raça negra, ou dela descendentes que, pela sua ilustração e costumes, se não distingam do comum daquela raça; e não indígenas, os indivíduos de qualquer raça que não estejam naquelas condições". Em resultado da Revisão Constitucional, este estatuto foi revogado em 1954, adoptou-se uma política integracionista e as colónias passaram a ter o nome e o estatuto jurídico de províncias ultramarinas. Este estatuto aprovado em 1954 foi definitivamente revogado em 1961.

${ }^{13}$ Ao longo dos anos o museu foi adquirindo várias designações: "Museu Gentílico" (1936), "Museu Etnológico" (1938), “Museu Etnográfico" (1940), “Museu Etnológico" de novo (1942) e “Museu do Dundo” (1943).

${ }^{14}$ Tal acontecia porque a Companhia não tinha autorização para venda de outros produtos além dos diamantes e por isso oferecia ou permutava a publicação com academias e museus. Depois da segunda guerra mundial, e por opção, a publicação não foi distribuída para o outro lado da “cortina de ferro" (Porto, 1999: 52).
} 
(Porto, 1999: 27). Trata-se da "primeira publicação científica sobre assuntos ultramarinos de origem portuguesa, vocacionada para distribuição internacional" (idem, ibidem). Segundo Barros Machado" ${ }^{15}$, depois de "explorada a área mais próxima do Dundo, organizaram-se verdadeiras expedições de colheita e reconhecimento (...) a regiões mais afastadas, como o Camaxilo (1937), o Canzar, o Alto Zambeze (1939), e finalmente (1946), o Alto Chicapa, o Tchiboco, pátria dos Quiocos" (Machado, 1995: 13). Até mais ou menos 1946 (?) "a Campanha Etnográfica constitui o modelo de trabalho mais corrente no Museu, cobrindo o duplo objectivo de reconhecimento etnográfico e de aquisição de objectos entre as populações locais" (Porto, 1999. 13). Pela leitura dos relatórios do museu é possível concluir que não existia propriamente um programa museológico restrito e que os interesses eram relativamente extensivos. Entre 1936 e 1946 ocorreram quatro campanhas etnográficas ${ }^{16}$ promovidas pelo museu. A sua colecção, constituída inicialmente por 496 objectos (reunidos por José Redinha) foi aumentada para 2.792 no ano seguinte, 3.613 em 1938, 4.887 em 1939, 5.040 em 1940 e mais de 5.500 no ano de 1942. A campanha seguinte (1946) ao Tchiboco (Alto Tchiapa) foi publicada, mas apenas em 1955 (Redinha, 1955a).

No decorrer destas campanhas, "Redinha ia fazendo relatórios, plenos de observações e de ilustrações" (Machado, 1995: 13). Segundo Nuno Porto, nas campanhas de recolha "a delimitação de áreas disciplinares não invalida a cooperação entre os seus membros", uma vez que "objectos etnográficos, espécimes biológicos ou vestígios arqueológicos são recolhidos em campanhas de longa ou curta duração efectuadas por responsáveis, ou delegados, de qualquer uma das áreas" (1999: 30). Por outro lado, podia haver colaboração dos sobas com estas campanhas. É o caso, por exemplo, do soba tchokwé Satxissenga que em 1942 se tornou "um dos primeiros colaboradores do Museu, desempenhando as funções de guia na Campanha de Reconhecimento da Rota da Expedição Portuguesa ao Muatiânvua" (Porto, 1999: 10).

No relatório anual do museu, referente a 1950, José Redinha refere que:

Os trabalhos do Museu tiveram duas fases diferentes: a primeira de angariamento e recolha de material, a segunda, em que nos encontramos, de Instalação e Ordenação do Museu.

\footnotetext{
${ }^{15}$ Barros Machado, um assistente da Faculdade de Ciências do Porto afastado pela política ditatorial, contribuiu no Dundo para a instituição e desenvolvimento do Laboratório de Investigações Biológicas.

${ }^{16}$ No período entre 1936 e 1941 a Sede da Diamang em Lisboa foi sendo informada acerca das Campanhas de recolha etnográfica.
} 
Na primeira fase do trabalho a tarefa exigia, em bloco, ser viajante, etnógrafo, aqueólogo, naturalista, angariador, e até 'cientista'; e, por isso fomos todas essas coisas, porque a missão o exigia, sem que fôssemos, afinal, nenhuma delas.

(...) Não somos, e temos bem presente, nem naturalista, nem etnógrafo, nem arqueólogo. Acontece, porém, que em África, a etnografia intervém em variadíssimos aspectos de actividade, uma vez que a colonização não dispensou a colaboração indígena e, muito mais intervém no nosso trabalho, que coincide com um Museu etnográfico, e contacto com os naturais. (...)

Museu do Dundo, 14 de Fevereiro de 1951, O Conservador, José Redinha (RA 1950: 42-43, citado em Porto, 1999: 23-24).

\section{O TRABALHO DE JOSÉ REDINHA DESENVOLVIDO NO MUSEU DO DUNDO}

José Redinha (1905-1983) foi um importante etnógrafo que produziu vários trabalhos e relatórios sobre diversas zonas culturais de Angola, primeiro como empregado (desde 1936) e depois como conservador do Museu do Dundo (a partir de 1942). Apesar de não ter formação universitária, o seu conhecimento das línguas nativas, as suas habilidades para o desenho e retrato e a sua intimidade com os chefes locais, foram consideradas qualificações excelentes (Porto, 2000: 41). Em 1945 é enviado para Lisboa para frequentar a cadeira de Etnografia da Faculdade de Letras, sob regência de Manuel Heleno, e realiza um estágio no Museu Arqueológico Leite de Vasconcelos, sob orientação do etnógrafo Luís Chaves (Porto, 1999: 26).

\subsection{ARTE TCHOKWÉ E ARTISTAS TCHOKWÉ}

O trabalho desenvolvido por Redinha contribuiu para que se começasse a falar em arte africana com regularidade no contexto de dominação colonial portuguesa. Todavia, é importante aqui referir que, inicialmente, para os seus construtores e/ ou utilizadores aqueles objectos não eram considerados arte e tinham apenas um carácter efémero e utilitário; outros porém, embora também não sendo considerados "arte" eram tomados como poderosos porque podiam ter um significado simbólico ou ser associados à realeza e ao poder dos sobas, uma vez que alguns deles eram oferecidos ao museu pelos sobas e suas famílias quando visitavam o Museu do Dundo. Contudo, já no início do século tinham contribuído para a visão de algumas manifestações africanas como arte os olhares de 
artistas como Pablo Picasso, Fernand Léger, Paul Guillaume, Amadeo Modigliani, Constantin Brancusi ou Henri Matisse, entre outros (Cantinho, 2005). Apesar disso, no contexto português, a “classificação da cultura material africana como arte, ainda que 'primitiva' ou 'negra'" era "largamente ignorada, na época (...) em favor de uma perspectiva remotamente difusionista que privilegia a influência portuguesa na produção de artefactos dos povos do Ultramar Português (cf. Macedo e Montalvor 1934)" (citado em Porto, 2000: 421). Até aos anos 50 não se falava em arte tchokwé e os objectos eram vistos apenas como curiosos. Para a mudança deste paradigma contribuiu inicialmente o trabalho de Redinha, que foi quem primeiro terá sugerido a existência de uma arte africana e de uma estética na expressão plástica dos tchokwé. Porém, tal não era reconhecido sequer pelos seus próprios autores. No relatório anual de 1953, Redinha refere que:

(...) Os artistas indígenas não têm senão um relativo interesse pela sua arte. Ser alfaiate, pedreiro ou motorista, apresenta-se para eles, coisa muito mais distinta do que serem artistas. Reconstituir o ambiente tribal antigo, onde, realmente, os artistas tinham uma alta cotação e prestígio, inclusive político, não é possível, por não ser fácil manter-se por seu pé.

O único processo viável, para o meio e circunstâncias locais, será acompanhá-los de perto, conduzi-los de modo a não alterar ou desorientar, e fazê-los conseguir bons resultados económicos, que os compense da execução de uma arte de onde não retiram brilho que os anime.

Nas zonas de colonização, falar de artistas indígenas apaixonados pela sua arte, é pura literatura. Não existem.

Também é difícil ressuscitá-los e muito mais criá-los. Pode-se, realmente, é retardar o seu desaparecimento, e tem sido esse o objectivo do Museu do Dundo (RA 1953: 19-20, citado em Porto, 1999: 64).

Para a concepção de arte tchokwé, o trabalho desenvolvido, por convite, a partir de 1956, pela historiadora de arte africana do Museu do Tervuren ${ }^{17}$ Marie-Louise Bastin teve um papel fundamental. O seu estudo, publicado em 1961 no n. 55 das Publicações Culturais do Museu do Dundo com o título Art Décoratif Tschokwe ${ }^{18}$, contribuiu para que a arte tchokwé passasse a ser reconhecida como tal pelos estudiosos e pelos entendidos no que à arte africana concerne.

Segundo Redinha, Angola lato senso apresenta duas grandes divisões culturais: "a metade norte da Província é a região da escultura" e a restante parte sul constitui "uma

\footnotetext{
${ }^{17}$ O Museu de Tervuren (Bélgica) foi o primeiro museu colonial europeu.

${ }^{18}$ Tal como a obra de Redinha, intitulada "Paredes pintadas da Lunda" (1953), este trabalho será reeditado brevemente em Angola.
} 
região cultural, caracterizada, do ponto de vista artístico, pelo ornato e pelo adorno" (1955b: 54). De um modo geral, Redinha descreve os objectos como tendo uma função determinante. Assim, por exemplo, refere que os humbis e os seus agregados fabricam "grais de madeira para milho (...), utensilagem para leite, panelas e púcaros de barro, esteiras de caniço rachado" [sic] (1955b: 40). São estes objectos com uma função determinante que Redinha classificaria de "não-artísticos", embora estes pudessem fazer parte das colecções do museu, sendo ilustrativos das actividades predominantes dos grupos humanos com os quais esteve em contacto. Neste sentido, é relevante a distinção que Redinha faz entre: "peças utilitárias" (peças e utensílios de uso doméstico, alfaias, ferramentas e armas de caça, objectos de usos individual), "peças artísticas" (estatuetas diversas, máscaras) e "peças produtoras de arte" (instrumentos musicais -membranofones, idiofones, cordofones) ([19... ]: 6-8) (figuras nos 4 e 5).

Para Redinha, a escultura é reveladora de um ofício que não existe na pintura. Por essa razão considera a pintura uma "arte popular" e a escultura uma "arte nobre" (1963: 25). No âmbito da escultura predominam as obras realizadas em madeira, mas existem também em pedra e marfim. A escultura pode expressar sentimentos, porém, segundo Redinha, as emoções não são produzidas por expressões fisionómicas, mas sim por "atitudes convencionais consagradas": "Os braços sobre a cabeça exprimem choro, dor, aflição; cruzados sobre o peito, desânimo, injustiça, desolação; apoiados nos joelhos e suportando a cabeça, meditação, pensamento, cogitação dos altos enigmas, etc" (1974: 229; 1970: 386).

E essa atitude que vemos na representação a que se chama frequentemente "o pensador" (figura n. 6). Para Redinha os agentes da arte em Angola foram, por excelência, o rito, a magia, as características sociais, o culto dos ancestrais e a veneração dos mortos (1963: 25). No seu trabalho podemos encontrar a descrição da evolução desde o tronco de madeira até à escultura final a partir de um conjunto de processos consecutivos (figura n.으 7). Segundo Redinha, o tronco adquire um significado transcendente - é-lhe atribuída uma "categoria de elemento espiritual" e o seu significado vai até "ao grau de o considerar como ser vivo" (1964: 25). Este etnógrafo verificou ainda que as maiores escolas de arte de madeira estavam associadas ao terreno da grande floresta, um facto que o levou a concluir acerca da existência de uma cultura florestal na base da arte da escultura de madeira (1964: 30). 
Segundo Redinha, podemos tomar como tipo da escultura dos lunda-quiocos a estatueta de mulher, cuja estatura média não excede os vinte e cinco centímetros de altura (figura n. 8). A representatividade deste tipo de escultura parece ser consequência do antigo regime social de organização de matriarcado. Além da escultura feminina, encontram-se neste grupo esculturas de caçadores, de tipos diversos, e de mascarados, assim como a escultura de frisos normalmente aplicada a móveis, como bancos e cadeiras.

Entre o que Redinha designa por "objectos escultóricos" destacam-se também as máscaras (figura n.o 9) que predominam nas zonas onde os ritos são mais intensos (1937: 34). No caso dos bailarinos mascarados o seu nome é sempre o nome da própria máscara que usam. Desse modo, ela "não é um complemento, mas sim a cabeça da personagem mascarada em todos os seus aspectos" (Redinha, 1956: 20).

\subsection{AS PAREDES PINTADAS DA LUNDA}

Segundo José Redinha, “as pinturas executadas nas paredes das casas constituem uma das manifestações artísticas mais espontâneas dos indígenas da Lunda ${ }^{19}$ ", são feitas por adultos e crianças, e algumas vezes por mulheres, e firmam uma "arte popular", não profissional, como acontece no caso da escultura (1953: 9). Por detrás da sua realização não existe um objectivo religioso ou mágico, mas apenas "decorativo e de entretenimento" (idem, p. 12). Estas pinturas "são feitas nas paredes de argila das habitações, geralmente do lado exterior", embora se possam encontrar também em paredes interiores (idem, p. 9). Esta forma de pintura em parede argilosa parecia ser recente entre os povos da Lunda e um resultado da influência da construção europeia. Em alguns lugares, por superstição (associavam-se as paredes de terra aos mortos), continuavam a construir casas apenas de madeira e colmo.

Para as pintar, continua Redinha, utilizam-se "substâncias corantes minerais e vegetais", sendo as cores mais vulgares "o vermelho, o preto, o branco, os ocres, castanhos, amarelos e cinzentos" (idem, p. 10). Tratam-se de obras efémeras, uma vez que são feitas na época seca e que desaparecem irremediavelmente com as primeiras chuvas. São como que um "jornal ilustrado" que relata a vida diária, mas também podem ter raízes no passado,

\footnotetext{
19 Estas pinturas também se encontravam noutras regiões como o Uele, entre os Azande, na Nigéria meridional, entre os Ibo e outros locais africanos.
} 
sobretudo as que se relacionam com a religião e o folclore (idem, p. 10). Estas pinturas são "geralmente geométricas", estilizadas e "realçadas por cores contrastantes" (idem, p. 11).

As principais críticas de Redinha relativamente a estas pinturas são devidas: às paredes de argila nem sempre serem "preparadas (alisadas) para receberem as pinturas e por isso o acabamento não fica cuidado" (idem, p. 10); à incapacidade de representar o volume, o que, segundo Redinha, permite concluir que este povo, no que a este assunto se refere, "não vai além de tantos outros povos primitivos" (idem, p. 11); a incapacidade de solucionar os problemas da perspectiva, tentando resolver o problema "figurando povoações ao alto" (idem, p. 12). No que diz respeito à interpretação das pinturas que reproduz no seu livro, Redinha refere ter seguido "aquela que os seus autores deram, sempre que foi possível obtê-la" (idem, p. 16).

As reproduções apresentadas neste texto (figuras nos 1, 10 e 11) e que fizeram parte da Exposição Lunda - Tchokwé, realizada em Dezembro de 2006 em Luanda, foram recolhidas por Redinha e "executadas sobre originais, directamente copiados das paredes onde se encontravam" e "para maior exactidão adoptou-se um método de pintura semelhante ao dos autores indígenas, usando-se (...) tintas baças e espessas" (idem, p. 16).

Por ocasião da inauguração da exposição "A arte dos quiocos - povo de Angola", a primeira consagrada à arte tchokwé, em 1958, na Casa de Portugal em Paris, que reuniu esculturas, fotografias, um fundo musical com temas do folclore recolhido pelo Museu do Dundo, e também uma série de pinturas murais dos tchokwés (recolhidas por Redinha) saiu no magazine Carrefour um comentário crítico elogioso de Frank Elgar. O sucesso deste conjunto expositivo viria mesmo a fazer com que a exposição se tornasse itinerante até 1965 (cf. Porto, 2003: 124).

Redinha cessou as suas funções em 1959 e veio a ser um dos membros fundadores da Secção de Etnografia do Instituto de Investigação Científica de Angola e um colaborador do Museu de Angola.

\subsection{LIMITAÇÕES DO TRABALHO DE JOSÉ REDINHA}

Redinha teve como referência o método de trabalho etnográfico de exploradores como Emil Torday, Léo Frobenius e Livingston, assim como Serpa Pinto, Capelo e Ivens e Henrique de Carvalho. Como acréscimo, o seu trabalho é encarado como uma continuidade 
do trabalho destes exploradores, que incluía o levantamento geográfico e humano dos territórios e a recolha de objectos etnográficos. Contudo, ainda que tenhamos em conta que a pacificação da Lunda tinha apenas $20 \operatorname{anos}^{20}$, o seu trabalho era na época já bastante anacrónico. Segundo o escritor José Osório de Oliveira, que a partir de certa altura passa a ser "o representante do Museu do Dundo nas operações de deslocamento do trabalho etnográfico sob a especificação de 'arte negra'” (Porto, 2000: 422), numa carta dirigida a Júlio de Vilhena a 28 de Novembro de 1953:

(...) O maior mal de José Redinha não é a falta de preparação teórica (escassez de cultura geral e de espírito filosófico, que o leva a inclinar se para a explicação Histórica em vez de procurar o sentidos das obras de Arte à luz da estética, e o dos fenómenos da antropologia cultural à luz da filosofia da Cultura), mas o seu actual desinteresse pela etnografia, a que se aplicou, com tão boa vontade, durante bastantes anos, quer na reprodução das paredes pintadas e das máscaras, quer em viagens de estudo como a que fez ao Tchiboco, quer na própria organização e arranjo do museu. Este tem, evidentemente, um arranjo imperfeito, pois algumas vezes atendeu-se mais ao sentido decorativo de que ao rigor científico e à função cultural. Isso pode provir, quer da tendência artística, de carácter decorativo, de José Redinha, quer da sua deficiente preparação, quer, ainda, da limitada extensão dos seus horizontes intelectuais, mas disso não é ele culpado. No que tem culpa é em subestimar a actividade etnográfica que the deu nome e a que deve o que é, levado pela ideia errada de que tem mais importância a história, a política indígena ou a administração. Lisboa, 28/11/53 (DCD ${ }^{21}$, J. O. Oliveira, 1953, citado em Porto, 2000: 426).

Todavia, o trabalho de Marie Louise Bastin, segundo N. Porto, vai "ultrapassar as limitações de Redinha ou Osório de Oliveira, e respectivas formulações (...) norteadas pela questão estética, com o propósito de elucidar o carácter racional, prescritivo e lógico", de um ponto de vista tchokwé, "quanto à utilização em determinados objectos, circunstâncias, sujeitos e acções, de marcas gráficas específicas" (Porto, 2000: 437). A historiadora vai tentar encontrar a recorrência de formas gráficas em diferentes suportes e "a autonomização ideográfica dessas formas (...) tende a produzir um código gráfico" reconhecível como cultura tchokwé e "identificável em objectos que incluem, enquanto tal, sujeitos humanos" (Porto, 2000: 437). M. L. Bastin conclui então que existe um "estilo tchokwé" e encontra motivos para sustentar a sua afirmação. Com o trabalho de M. L. Bastin

\footnotetext{
${ }^{20}$ Sobre a história das campanhas de pacificação de Angola, vide Pélissier (1986), segundo o qual as campanhas na Lunda duraram até 1926.

${ }^{21}$ Documentação cultural diversa.
} 
o Museu do Dundo passou a ocupar um lugar central e a sua "posição subalterna em termos etnográficos" foi "substituída por uma posição central em termos de Arte Tsokwe" (Porto, 2000: 439). Por outro lado, com estes novos dados, a Diamang encontrava mais um motivo para se regozijar do sucesso do seu empreendimento.

\section{CONSIDERAÇÕES FINAIS}

A exposição que visitei em finais de 2006 em Luanda, apesar de conter representações figurativas publicadas em 1953 num contexto particular, foi percepcionada pelos visitantes como uma exposição de arte e não como uma mera reconstituição, ou curiosidade, ou ainda contextualização histórica do passado. Além disso, e apesar de sabermos que esse passado foi um passado colonial, não havia propriamente referências ao colonialismo, ou aos seus aspectos negativos, nem aos efeitos que os contactos culturais entre diferentes grupos e as tensões suscitadas nesse período levaram e de que forma tais fenómenos poderão ter influenciado algumas práticas, inclusivamente as que estão ligadas a manifestações como estas. Porém, e como ilustra o caso desta exposição, alguns fenómenos e elementos tidos como novos constituem-se na realidade em continuidade com o passado, embora essa possa não ser reconhecida de imediato ou verbalizada. Quer queiramos, quer não, as lembranças do que foi o colonialismo acabam por emergir, como uma espécie de fantasma e uma coisa parece certa: a arte tchokwé, que acabou por ser reconhecida como tal ainda no contexto colonial, está ligada ao Terceiro Império Português, à Diamang, ao Museu do Dundo e ao trabalho de pessoas como José Redinha.

Mas a arte parece estar aqui também ligada com a política, por um lado, e com a reivindicação de identidade, por outro. Hoje em dia, muitas vezes a cultura, e especificamente a arte, torna-se uma preocupação das elites, ou seja, de uma minoria letrada e favorecida, muitas vezes pelo próprio Estado. Já para os angolanos que vivem da economia informal, que não têm casa ou vivem em muceques (que se avistam facilmente nos arredores da capital), ou são deslocados e órfãos de guerra, e que constituem a maioria da população de Luanda, a arte não fará certamente parte das suas preocupações mais prementes. No caso desta exposição não é propriamente a reivindicação de objectos ou artefactos que está em causa, mas sim a reivindicação de determinados desenhos, feitos por pessoas de um grupo, que passaram a ser considerados como inspiradores e determinantes 
no âmbito da arte que se produz actualmente em Angola. O que me desperta atenção aqui é a reivindicação da arte tchokwé na actualidade e a afirmação contemporânea da etnicidade tchokwé. Porém, como referiu o sociólogo angolano Víctor Kajibanga (2000):

(...) O território que hoje se chama Angola" situa-se "numa encruzilhada de civilizações e culturas milenares, onde se destacam: 'a dos caçadores e agricultores das grandes savanas da África Austral (antepassados dos actuais Lunda, Cokwe, Lwena, Luvale, entre outros); a dos criadores de gado bovino que se estende dos Grandes Lagos às zonas tropicais secas e desérticas da África Austral (Helelo, Nkhumbi e Ambó); os Povos Ovimbundu (língua umbundo) e Ambundu (língua kimbundu) ${ }^{22}$.

Assim, se reflectirmos sobre esta realidade, somos levados a colocar algumas "interrogações e inquietações", que segundo Kajibanga são as seguintes:

(...) A primeira consiste em saber se podemos falar de uma cultura angolana como fenómeno global ou então encará-la como projecto, isto é, um fenómeno em formação; a segunda consiste em detectar as linhas de continuidade e descontinuidade entre as culturas étnicas e o projecto de cultura nacional, tendo em atenção a realidade pluriétnica angolana; a terceira levanta o problema do diálogo ou da alteridade entre o projecto de cultura nacional com as culturas étnicas transnacionais. (Kajibanga, 2000).

Perante estas formulações pergunto: o que poderá estar por detrás da organização desta exposição passados 53 anos da publicação da obra de José Redinha, uma figura do colonialismo português? Como se conseguiu levar a cabo com sucesso tal iniciativa? Esquecendo o passado? Ou será que é porque José Redinha, embora compactuando com o colonialismo, era bem tolerado pelos angolanos? Ou será porque, afinal, José Redinha deixou uma obra considerável acerca dos lunda-tchokwé? O que procuravam alguns visitantes ao percorrer as várias salas dedicadas à Trienal de Luanda que se dividiam pela capital angolana? A sua identidade ou as suas origens? Com esta exposição estar-se-á simplesmente a lembrar o passado ou, de uma forma mais complexa, estar-se-á a reactualizar o passado ou ainda a presentificá-lo?

Repare-se que as serigrafias ali expostas foram, embora copiadas das imagens do passado, elaboradas no presente. Todas elas foram redimensionadas e emolduradas. Além disso, foram expostas fora do seu contexto, sem o nome dos seus autores ou dos grupos que as elaboraram e sem a sua localização. Por outro lado, na exposição nada nos é dito acerca

\footnotetext{
${ }^{22}$ Neto, 1995/1996: 6. Citado em Kajibanga, 2000.
} 
do contexto de realização das obras, da explicação dos desenhos e da razão pela qual foram elaborados. Tal poderá dever-se ao facto de que o trabalho de Redinha tinha, ele próprio, limitações e não tentou responder a todas estas questões? Como explicar esta ausência de informação quase total acerca dos desenhos? Será que eles valem por si mesmos e, tal como acontece em muitas exposições de arte contemporânea, carecem de explicações e apenas alguns iluminados como os críticos de arte estão habilitados a emitir comentários acerca das mesmas?

Contudo, o mais interessante ainda parece ser o facto de aqueles desenhos, produzidos no contexto colonial, com tudo o que isso implica, serem vistos como o passado dos tchokwé e, extensivamente, dos angolanos. E se eles estão ali, passíveis de serem vistos, permitindo a alguns angolanos terem um contacto com o seu passado cultural, ou folclórico, foi porque eles foram recolhidos, registados e poupados da influência europeia e da sua destruição e também da própria destruição causada pelo seu carácter efémero, uma vez que, como foi referido, aqueles desenhos seriam destruídos posteriormente na época das chuvas.

No discurso ${ }^{23}$ da Festa Grande Anual Indígena de 1951, organizada pelo Museu do Dundo, José Redinha, enquanto Conservador do Museu, refere:

\begin{abstract}
Bem contrariamente ao que foi admitido durante longo tempo, os povos de África estão muito longe de serem um povo sem história. $E$ a história da tribo kioka desde o início do séc. XVIII até finais do séc. XIX é, sem dúvida, uma sucessão de audácias primitivas, marcadas por enormes aventuras (...). (...) Os kiokos são, presentemente, uma das mais importantes tribos da Província.

(...) A colonização da Lunda, onde a 'Diamang' toma um lugar eminente, é um capítulo moderno sobre a pretérita história dos naturais. (FGAI 1951: 97-98, citado em Porto, 1999: 85-86).
\end{abstract}

Tal como os elementos culturais que José Redinha encontrou e considerou fazerem parte da história dos tchokwé no contexto colonial, também aquela exposição elaborada a partir de desenhos por ele copiados é percepcionada como fazendo parte da história dos tchokwé e, num nível superior, dos próprios angolanos. Paralelamente a este fenómeno têm surgido recentemente discursos que evocam o passado comum de Portugal e das suas excolónias, que ressaltam a partilha de uma língua e de alguns aspectos culturais que podem

\footnotetext{
${ }^{23}$ Estes discursos (do Director Geral na Lunda, do Governador da Circunscrição, do Conservador do Museu) eram lidos em português e traduzidos para cokwé (Porto, 1999: 85).
} 
incluir a religião, a gastronomia ou as artes, como a música, entre outros fenómenos, e que constituem processos que merecem ser oportunamente investigados e analisados. De facto, aquilo que parece estar circunscrito a um tempo e um espaço, pode ter muitas vezes uma origem muito distante. Além disso, em alguns aspectos verificamos que existe uma certa continuidade entre o período colonial e o pós-colonial, tanto ao nível conceptual como ao nível das práticas, no que se refere à arte. Estas são algumas das questões para as quais podemos tentar encontrar respostas e reflectir sobre o que se está a passar hoje em Angola em termos de aspectos que se relacionam com a identidade, a influência cultural, a hibridez e o pós-colonialismo. Neste caso, e mais importante que tudo, conhecer o passado é fundamental para dar um sentido ao presente e delinear o que se quer construir no futuro.

\section{BIBLIOGRAFIA}

AREIA, M. L. R. de. 1995. "Introdução". In Diamang. Estudo do Património Cultural da ExCompanhia de Diamantes de Angola. Coimbra: Centro de Estudos Africanos. Departamento de Antropologia. P. 7-10.

BALANDIER, Georges. 1955. Sociologie Actuelle de L'Afrique Noire. Dynamique des changements sociaus en Afrique Centrale. Paris: Presses Universitaires de France.

CANTINHO, Manuela. 2005. "Arte angolana e lusofonia". Dicionário Temático da Lusofonia. Lisboa (?): Texto Editores, ACLUS.

CARRISSO, Luiz W. 1932. A Missão Botânica da Universidade de Coimbra à Colónia de Angola, em 1927. Coimbra: Imprensa da Universidade.

COOPER, Frederick. 2005. Colonialism in Question. Theory, Knowledge, History. Berkeley: University of California Press.

KAJIBANGA, Victor. S. d. Sociedades Étnicas e Espaços Socioculturais (uma contribuição ao estudo da problemática das culturas étnicas e da cultura nacional em Angola). Síntese de comunicação apresentada no Instituto de África da Academia de Ciências da Rússia e na Universidade Estatal de Moscovo, por ocasião do 25 Aniversário da Independência Nacional da República de Angola (Moscovo, Novembro de 2000), disponível na Internet: http://www2.ebonet.net/vkajibanga/docs/sintesecomunicacao.doc

LEITE DE CASTRO. 1929. Companhia de Diamantes de Angola. Lisboa: Diamang.

MACHADO, A. de Barros. 1995. "Notícia Sumária sobre a Acção Cultural da Companhia de Diamantes de Angola". In Diamang. Estudo do Património Cultural da Ex-Companhia de Diamantes de Angola. Coimbra: Centro de Estudos Africanos. Departamento de Antropologia. P. 11-28. 
MARTINS, Maria do Rosário R.; GIRÃO, M. das Dores. 1995. "Colecção Etnográfica". In Diamang. Estudo do Património Cultural da Ex-Companhia de Diamantes de Angola. Coimbra: Centro de Estudos Africanos. Departamento de Antropologia. P. 29-32.

Museu Antropológico da Universidade de Coimbra (MAUC). 1995. Diamang - Estudo do Património Cultural da Ex-Companhia de Diamantes de Angola. Coimbra: MAUC.

PÉLISSIER, René. 1986. História das Campanhas de Angola, Resistências e Revoltas, 18451941. Vol. I. Imprensa Universitária. Lisboa: Editorial Estampa.

PORTO, Nuno. 1999. Angola a Preto e Branco. Fotografia e Ciência no Museu do Dundo, 1940-1970. Coimbra: Museu Antropológico da Universidade de Coimbra.

PORTO, Nuno. 2000. Modos de objectificação da dominação colonial: o caso do Museu do Dundo, 1940-1970. Dissertação de Doutoramento para a obtenção do grau de Doutor em Antropologia apresentada à Faculdade de Ciências e Tecnologia da Universidade de Coimbra. Coimbra: Ed. do autor.

PORTO, Nuno. 2003. "Le musée en tant que technologie d'enchantement: le travail muséal à la Compagnie des Diamants d'Angola". In Les Arts Premiers, Arquivos do Centro Calouste Gulbenkian. Vol. XLV. P. 123-132.

REDINHA, José. ([19...]). Álbum Etnográfico. Angola: Ed. C.I.T.A.

REDINHA, José. 1937. As Máscaras Africanas (esboço).

REDINHA, José. 1953. Museu do Dundo: subsídios para a história, arqueologia e etnografia dos povos da Lunda - Paredes Pintadas da Lunda. Lisboa: Serviços Culturais, Companhia de Diamantes de Angola. Publicações Culturais, n.ㅇ 18.

REDINHA, José. 1955a. Museu do Dundo: subsídios para a história, arqueologia e etnografia dos povos da Lunda - A Campanha Etnográfica do Tchiboco (Alto Tchicapa). 2 Volumes. Lisboa: Serviços Culturais, Companhia de Diamantes de Angola. Publicações Culturais, n.ㅇ 19.

REDINHA, José. 1955b. "Os povos de Angola e as suas culturas". In Museu de Angola. Coleç̧ão Etnográfica. Lisboa: Publicações do Museu de Angola.

REDINHA, José. 1956. "Máscaras de madeira da Lunda e Alto Zambeze". In Museu do Dundo. Subsídios para a História, Arqueologia e Etnografia dos Povos da Lunda. Lisboa: Companhia de Diamantes de Angola (Diamang).

REDINHA, José. 1963. “L’art Angolais”. La Revue Française. Angola. N. 156. Septembre. REDINHA, José. 1964. "Um esquema evolutivo da escultura antropomorfa angolana". In Subsídios Etnográficos. Luanda: Centro de Informação e Turismo. P. 23-30. 
REDINHA, José. 1970. “Angola”. In Arte Popular em Portugal, Ilhas Adjacentes e Ultramar. Lisboa: Verbo.

REDINHA, José. 1974. Etnias e Culturas de Angola. Luanda: Instituto de Investigação Científica de Angola.

TELO, António José. 1994. Economia e Império no Portugal Contemporâneo. Lisboa: Cosmos.

Textos disponíveis na internet:

http://angolarussia.ru/press/angoflash/angoflash_2006-11-28.doc.

http://www.trienal-de-luanda.net/index.php?cat=2. 